\title{
Role of Polysaccharides on Mechanical and Adhesion Properties of Flax Fibres in Flax/PLA Biocomposite
}

\author{
Gijo Raj, Eric Balnois, Christophe Baley, and Yves Grohens \\ LIMATB (Laboratoire d'Ingénierie des MATériaux de Bretagne), Centre de Recherche, Université de Bretagne Sud (UBS-Ueb), \\ Rue de Saint Maudé, 56321 Lorient Cedex, France \\ Correspondence should be addressed to Eric Balnois, eric.balnois@univ-ubs.fr
}

Received 10 January 2011; Accepted 2 March 2011

Academic Editor: Susheel Kalia

Copyright ( 2011 Gijo Raj et al. This is an open access article distributed under the Creative Commons Attribution License, which permits unrestricted use, distribution, and reproduction in any medium, provided the original work is properly cited.

The effect of alkali and enzymatic treatments on flax fibre morphology, mechanical, and adhesion properties was investigated. The multilength scale analysis allows for the correlation of the fibre's morphological changes induced by the treatments with mechanical properties to better explain the adherence properties between flax and PLA. The atomic force microscopy (AFM) images revealed the removal of primary layers, upon treatments, down to cellulose microfibrils present in the secondary layers. The variation in mechanical properties was found to be dependent, apart from the crystalline content, on interaction between cellulose microfibrils and encrusting polysaccharides, pectins and hemicelluloses, in the secondary layers. Finally, microbond tests between the modified fibres and PLA emphasize the important role of the outer fibre's surface on the overall composite properties. It was observed here that gentle treatments of the fibres, down to the oriented microfibrils, are favourable to a better adherence with a PLA drop. This paper highlights the important role of amorphous polymers, hemicellulose and pectin, in the optimisation of the adhesion and mechanical properties of flax fibres in the biocomposite.

\section{Introduction}

Research for environmental friendly alternatives has led the composite community to develop new "ecobiocomposites," made from natural fibres and biodegradable polymer matrices, such as polylactic acid (PLA) [1-3]. It was reported that the specific Young's modulus of PLA/Flax biocomposite $(6.52 \pm 0.075 \mathrm{GPa}$ for $25 \%$ fibre volume fraction) can be as close to that of glass/polyester composites (7.762 \pm $0.0638 \mathrm{GPa})$ [1] and makes them suitable for interesting applications.

Even though natural fibres have ecofriendly credentials, they present some major drawbacks, such as poor thermal stability, anisotropic resistance, high moisture absorption heterogeneity, and in some cases poor incompatibility with polymer matrices [3]. These drawbacks prevent the use of natural fibre reinforcements in high performance structural composite applications and limit, up to now, their use for nonstructural parts. The complex chemical and physical structure of natural fibres $[4,5]$ is certainly responsible for these limitations which may be overcome using different chemical or physical surface treatments.

A detailed description of the flax fibre structure can be found in the literature $[4,5]$. Briefly, a flax fibre consists of (i) a middle lamella region, principally made up of pectin, with small quantities of lignin that ensures bundle cohesion, (ii) a primary cell wall which forms $\sim 10 \%$ of the fibre's diameter and mainly consists of cellulose microfibrils embedded in a matrix of pectin, hemicelluloses, and small quantities of lignin $[5,6]$, and (iii) a secondary cell wall, which makes up $90 \%$ of the cell cross section and mainly consists of three layers of cellulose microfibrils, with a mean axial orientation of $10^{\circ}$, bounded with pectin and hemicellulose. In this layer, pectin and hemicellulose are forming an interphase between cellulose microfibrils $[5,7]$ and are thus called "encrusting polymers." Cellulose microfibrils with typical diameters about 25-30 nm [4] consist of highly ordered crystalline cellulose zones (with typical Young's modulus up to $143 \mathrm{Gpa}$ [8]), in which cellulose crystals are arranged periodically and longitudinally along the fibre's axis, interconnected by 
amorphous cellulose zones. An important issue concerns the hierarchical organisation and structuration of different polysaccharides in the different layers of the fibre and the structural difference between primary and secondary layers. This point is very important to better understand the mechanical and surface properties of flax fibre and consequently to better understand the effect of specific treatments to improve the mechanical properties of the fibrereinforced composite.

During the past decade, numerous works have been published in the literature concerning modifications of flax fibres to improve the interface adhesion with a polymeric matrix [9, 10]. Among the different chemical treatments, alkali treatment of flax fibres was found to be simple and efficient in improving the adhesion with polymer matrices $[11,12]$. This treatment is known to remove amorphous polysaccharides such as hemicellulose, pectin [5], lignin [13], and separate fibre bundles into elementary fibres. Additionally, alkaline solution reacts not only with noncellulosic materials, but also with cellulosic components creating large cellulose lattices, which can be converted to new crystalline structures (cellulose II) [12]. Another effect of mercerisation is the possible depolymerisation of the native cellulose type I molecular structure into short-length crystallites [14]. This last effect has a direct negative effect on the fibre strength and stiffness [13].

Recently, enzymatic treatments involving the use of mainly pectinase enzymes have gained the attention of the scientific community as an environmental friendly treatment on flax fibres [15]. These treatments were found to be efficient in removing the shive and epidermal tissues of fibres, as characterized by optical and Scanning Electron Microscopy studies [16]. Commercially available enzyme preparations mainly contain pectinase, as well as some quantities of hemicellulase and cellulase enzymes. Enzymes rich in pectinase and poor in cellulase are generally more suited to avoid any cellulose alteration within the fibre. However, it has been shown in a recent work, using X-ray scattering techniques, that cellulase enzymes act only on the surface of cellulose microfibrils and are not able to penetrate into nanopores of the cellulose crystallites without affecting the degree of crystallinity [17].

Although modifications of flax fibres by both chemical and enzymatic methods result in improved mechanical properties of the biocomposite, a detailed investigation of the relation between the morphological changes of the fibre and the resulting properties, at different length scales, is necessary to better understand the complex properties of such heterogeneous fibres. Generally, the overall properties of the composites are probed by macroscopic and indirect analysis such as mechanical tests $[11,18]$, water sorption studies [19], or chemical analysis [20, 21]. A major limitation of such macroscopic studies comes from the fact that they do not give a direct and clear relationship between the structural modifications of the fibre and their consequence on the fibre and composite properties. Recently, nanoscale studies of flax fibre using atomic force microscopy have emphasized the relevance of a multiscale investigation on such materials and provide valuable morphological and quantitative data to characterize the fibre's surface properties [22, 23]. These works were complementary to traditional determination of interfacial energies using contact angle measurements, which is difficult to experimentally perform on heterogeneous samples such as that of flax fibres.

The aim of this paper is to highlight the significant factors acting on the interfacial adherence in biocomposites. The morphology of alkali- and enzymatic-treated fibres is investigated at different length scales, in order to better understand the relationship between the structure and the mechanical properties of the flax fibre. The adhesion properties at the fibre-polymer matrix interface are followed by microbond pull-out tests and force-volume adhesion mapping and discussed in the framework of the morphological and chemical modification induced by the treatments.

\section{Materials and Methods}

2.1. Alkali Treatment of the Flax Fibres. Dew-retted flax fibres (variety Hermes) grown in the Normandy region (France) were used in this study. Flax fibres were initially soaked in $\mathrm{NaOH}$ solutions $(1 \%, 3 \%, 5 \%$, and $10 \%)$ for 20 minutes at $23^{\circ} \mathrm{C}$. The fibres were filtered and washed thoroughly in Milli-Q water before being rinsed in a very diluted solution of $\mathrm{HCl}(0.01 \mathrm{M})$ to remove excessive $\mathrm{NaOH}[12]$ and washed again with Milli-Q water before drying in vacuum at $65^{\circ} \mathrm{C}$ for 3 hours.

2.2. Enzyme Treatment of Flax Fibres. Enzyme treatments of flax fibres were carried out using a pectinase enzyme, made from Aspergillus aculeatus, Pectinex Ultra SPL (activity 9500 units/mL, Sigma Aldrich). The enzyme solution was diluted to a concentration of $20 \%$ in an acetate buffer solution (Sigma Aldrich) having a pH of 4.6 [22]. About $1 \mathrm{~g}$ of flax fibres was treated in $100 \mathrm{~mL}$ of the $20 \%$ enzymatic solution at $40^{\circ} \mathrm{C}$. Fibres were then taken out of the treatment at intervals of $5 \mathrm{H}$ and $18 \mathrm{H}$, washed at least 5 times in Milli$\mathrm{Q}$ water, and dried in vacuum at $65^{\circ} \mathrm{C}$ for 5 hours before any analysis.

2.3. Scanning Electron Microscopy (SEM). Morphology of raw-, alkali-, and enzyme-treated flax fibres was examined using a Jeol JSM $6460 \mathrm{LV}$ Scanning electron microscope. Flax fibre samples were metallised (Edwards Scancoat six metallizer) for 10 minutes prior to SEM imaging.

2.4. Atomic Force Microscopy (AFM). AFM experiments were conducted using a commercial Multimode Nanoscope IIIa atomic force microscope (Veeco, USA). Images were acquired in tapping mode (TM-AFM) under ambient conditions $\left(23^{\circ} \mathrm{C}\right.$ and $\left.\mathrm{RH} 56 \%\right)$ using silicon tips (LTESP, Veeco). Samples were prepared by gluing an elementary flax fibre by their two extremities on a magnetic steel disc in order to keep it fixed during image acquisition.

Force volume (FV) mode was used to construct an adhesion force map of the various fibres. In FV mode, a contact mode image of the fibre's surface was first made using a conventional contact mode tip (spring constant $0.57 \mathrm{~N} / \mathrm{m}$ ). 
Force maps were captured in the "relative trigger" mode to ensure that the maximum loaded force exerted on the sample is the same in every force plot. The maximum cantilever deflection was fixed at $160 \mathrm{~nm}(91 \mathrm{nN})$. The image $\mathrm{XY}$ resolution parameter, sample/line, was kept at 128, and the number of force/line was 64 . Thus, for a scan line of $1.6 \mu \mathrm{m}$, force plots were recorded at every $25 \mathrm{~nm}$.

2.5. Infrared (IR) Spectroscopy. Infrared (ATR-IR) spectroscopy (IR Perkin Elmer spectrometer) was performed on raw-, $\mathrm{NaOH}-$, and enzyme-treated flax fibres using the attenuated total reflectance method with a mountable unit (Golden Gate). Spectra were acquired with an accumulation of 25 scans and were recorded in the transmittance mode in the range $400-4000 \mathrm{~cm}^{-1}$.

2.6. Single Fibre Tension Test (SFTT). Flax single fibres were manually extracted and glued at both ends onto a piece of paper which was already punched to make a $10 \mathrm{~mm}$ hole (equal to the initial length $L_{0}$ of the fibre). The mean diameter of flax fibres was determined by optical microscopy and obtained by analysing at least 15 different zones on each fibre. A minimum of fifty fibres, for each sample (raw-, $\mathrm{NaOH}-$, and enzymatic-treated fibres), were analysed. The longitudinal Young's modulus of the flax fibres was determined from the tensile loading of elementary flax fibres respecting the standard methods (NFT 25-704, ASTM 3379$75)$, that also takes into account the compliance of the system. The tension experiments were performed in a tensile testing machine (MTS Synergie 1000) equipped with a load cell capture that allows for measurements in the range of $0-2 \mathrm{~N}$ with an accuracy of $0.01 \%$. Loading rate was kept constant at $1 \mathrm{~mm} / \mathrm{min}$ throughout all experiments.

2.7. Wide-Angle X-Ray Scattering (WAXS). X-ray scattering experiments were performed on a custom-built SAXS/WAXS machine equipped with a Rigaku MicroMax-007 HF rotating anode generator $(\lambda=1.54 \AA)$. The size of the pointlike X-ray beam on the sample was approximately. $300 \mu \mathrm{m}$. The 2D WAXS data were collected using X-ray sensitive Fuji image plates with a pixel size of $100 \times 100 \mu \mathrm{m}^{2}$. The modulus of the scattering vector $s(s=2 \sin \theta / \lambda$, where $\theta$ is the Bragg angle) was calibrated using three diffraction orders of silver behenate. The data reduction and analysis including geometrical and background correction, visualization, and radial integration of the $2 \mathrm{D}$ diffractograms were performed using home-built routines designed using the IgorPro software package.

2.8. Microbond Test. The adherence strength between the flax fibres and the PLA matrix (Biomer L9000) was estimated by calculating the apparent interfacial shear stress (IFSS) values obtained from microbond tests on a minimum of ten pull-out experiments. A homogeneous PLA polymer microdroplet $(<200 \mu \mathrm{m})$ was deposited on the surface of the flax fibre. In order to achieve this microdroplet, a microknot was made on the flax fibre with a microfilament of PLA. The setup was placed in an oven preheated at $190^{\circ} \mathrm{C}$ for 10 minutes. The sample was then immediately taken from the oven and quenched at room temperature. Prior to any tests, the diameter of the fibre near the PLA droplet, the embedded length of the fibre, and the drop height were measured using an optical microscope. Pull-out experiments were performed on a tensile testing machine (MTS Synergie 1000, load cell $2 \mathrm{~N}$ ). On the lower clamp, a homemade X-Y translator with two sharp knife edges was mounted. The microdroplet was brought just under these knife edges, and the knife blades were brought close together so that the blades just touch the upper end of the droplet [21]. Tensile loading was applied at the rate of $0.1 \mathrm{~mm} / \mathrm{min}$.

\section{Results and Discussion}

3.1. Morphology of the Flax Fibres. SEM images of raw and treated bundles (Figures 1(a), 1(b), and 1(c)) provide a macroscopic investigation of the morphology of the outer surface of the fibres. Figure 1(a) shows the bundle structure of raw flax fibres formed by elementary fibres held together mainly by pectin, lignin, and amorphous polymers found in the primary cell wall and in the middle lamellae region [5]. On the other hand, the two modified fibres, following $\mathrm{NaOH}$ and enzymatic treatment (Figures 1(b) and 1(c), resp.), appeared to be well separated.

Figures 1(d), 1(e), and 1(f) show SEM images of elementary fibres of raw-, $\mathrm{NaOH}-$, and enzyme-treated flax respectively. The surface of the treated fibres (Figures 1(e) and 1(f)) appears free of any residual particles, homogeneous and smoother, which reveal the efficiency of both treatments in removing some large particles and entities present on the raw fibre (Figure 1(d)). This result contrasts with some earlier studies of the effect of $\mathrm{NaOH}$ on the structure of natural fibres, which reported a drastic change of the fibre morphology that led to a decrease of the fibre diameter and the development of a rough and irregular surface [24]. It should be mentioned that in some cases, the $\mathrm{NaOH}$ treatment was more severe (higher concentration) [13] and less controlled (time and temperature) [21] than in more recent studies [12].

Atomic force microscopy was used to observe the surface of the flax fibres with a nanometer resolution. Tapping mode (TM) AFM images reveal similar trends as those observed by SEM (Figure 2). Large globular entities or particles that envelop the fibre's surface can be observed on raw fibres (Figure 2(a)). Upon treatment, these particles disappeared, and the flax fibre's surface becomes relatively smooth. The alkali treatment yields a cleaning effect of the fibre's surface. For a concentration of $5 \%$, the AFM image reveals an unidirectional orientation of microfibrils in the secondary layer (Figure 2(b)). At the highest $\mathrm{NaOH}$ concentration $(10 \%)$, a better resolution of the oriented microfibrils is obtained, with typical diameters between 20 and $40 \mathrm{~nm}$ (Figure 2(c)). These oriented fibrils are all aligned within a similar direction to the main fibre axis. These entities correspond well to the description of crystalline cellulosic microfibrils within the secondary cell wall of flax fibre, both in terms of size and orientation [4]. 


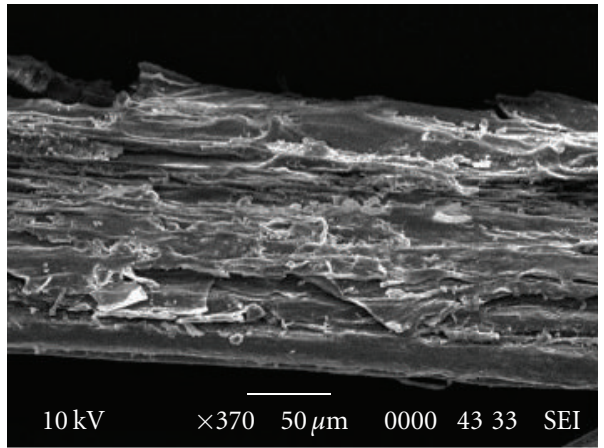

(a)

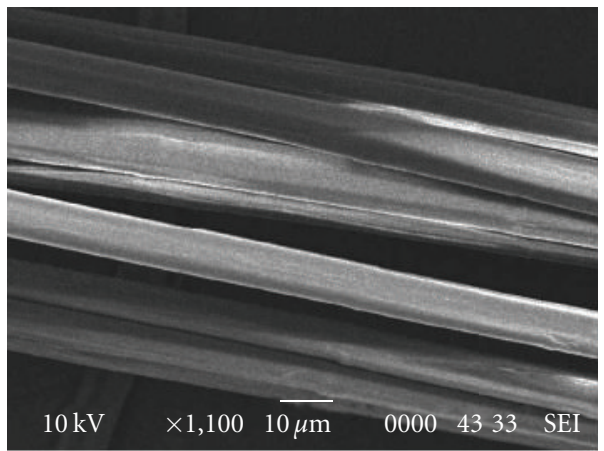

(c)

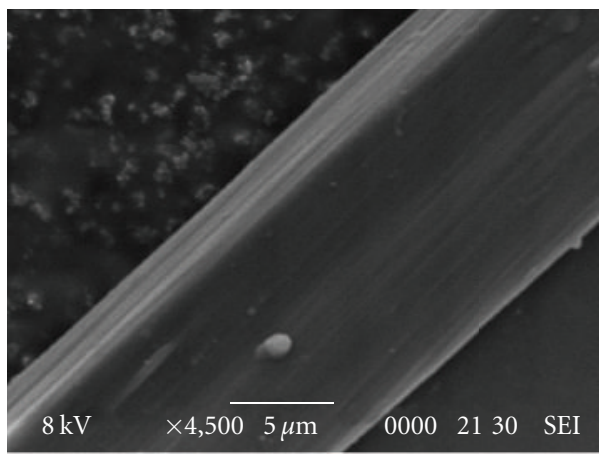

(e)

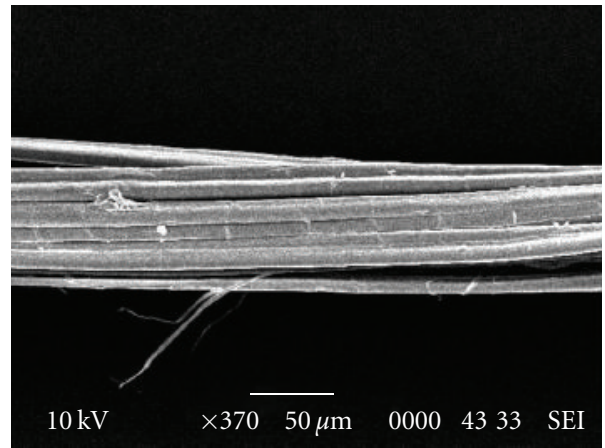

(b)

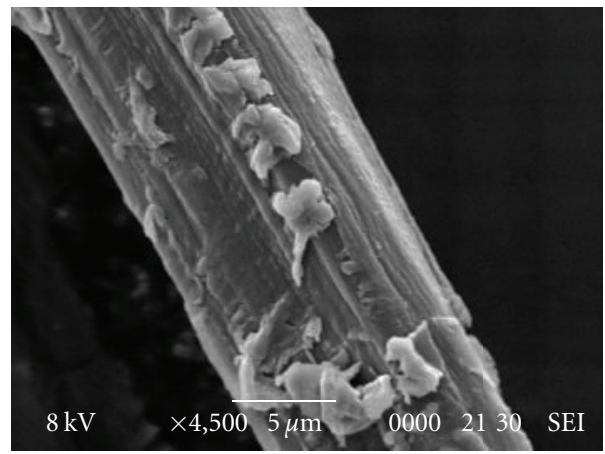

(d)

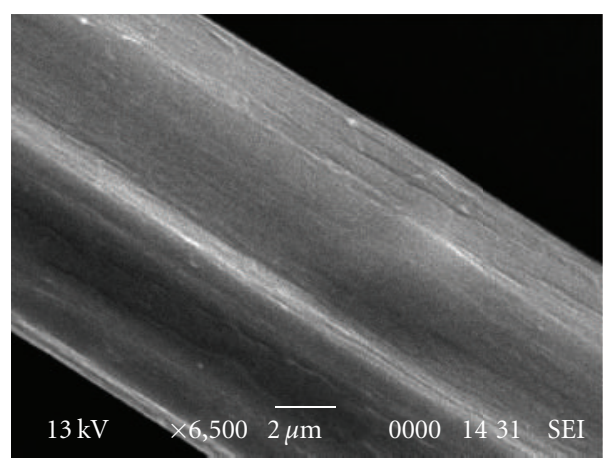

(f)

Figure 1: SEM images of flax fibres: (a) raw flax bundle, (b) 10\% NaOH-treated bundle, (c) $18 \mathrm{H}$ Enzyme-treated bundle, (d) raw elementary fibre, (e) $10 \% \mathrm{NaOH}$-treated elementary fibre, and (f) $18 \mathrm{H}$ enzyme-treated elementary fibre.

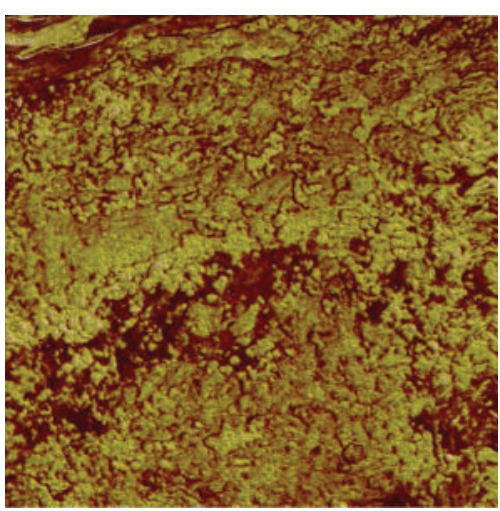

(a)

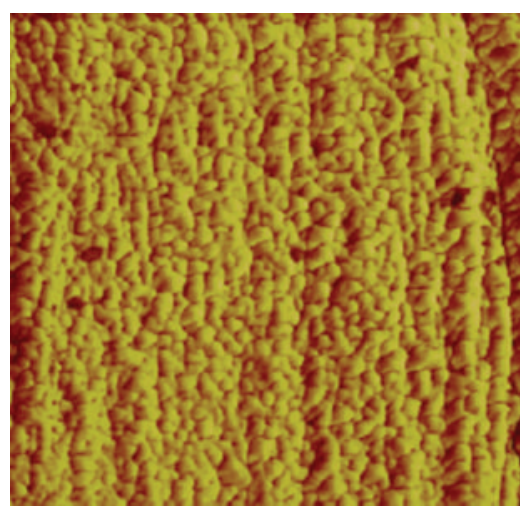

(b)

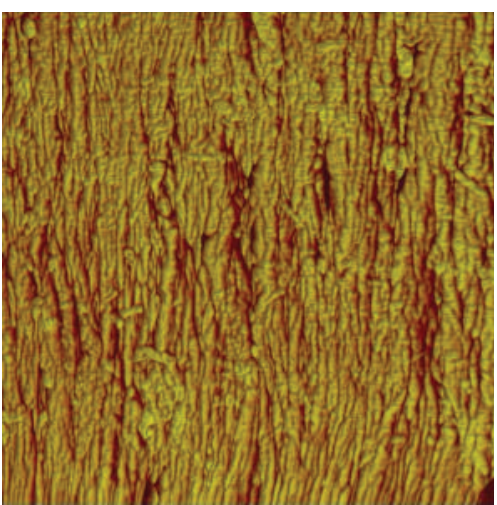

(c)

Figure 2: TM-AFM phase images (scan size of $4 \mu \mathrm{m}^{2}$ ) of (a) raw-, (b) $5 \% \mathrm{NaOH}-$, and (c) $10 \% \mathrm{NaOH}$-treated flax fibres. 


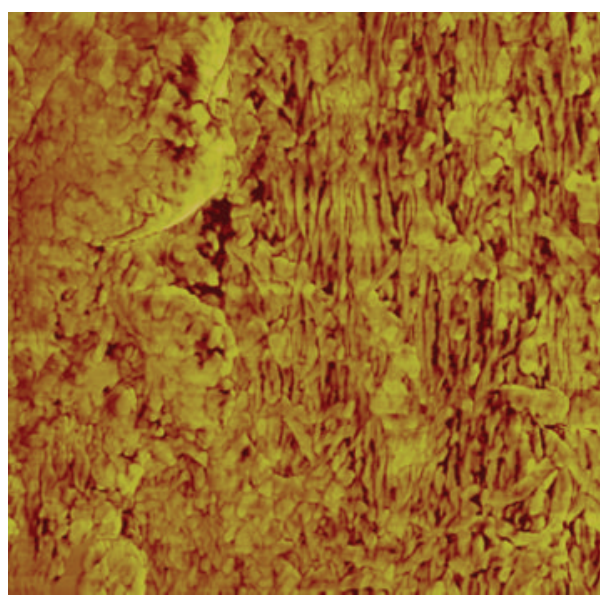

(a)

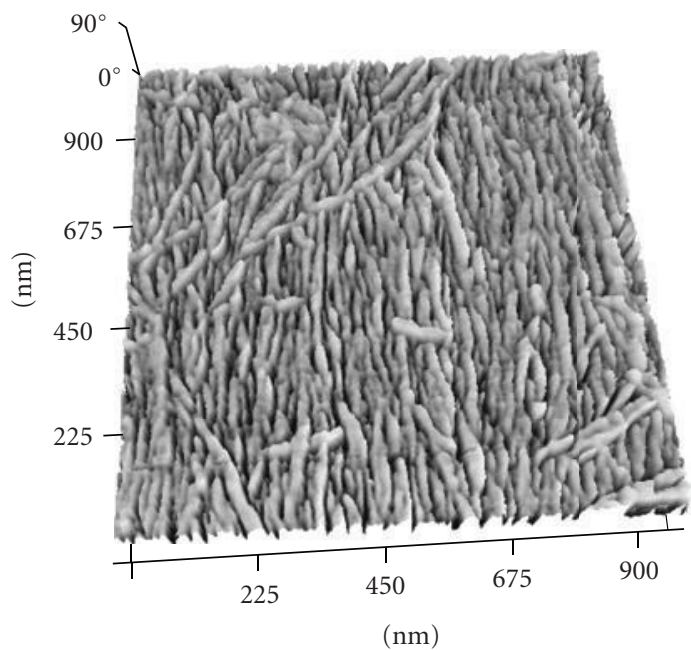

(c)

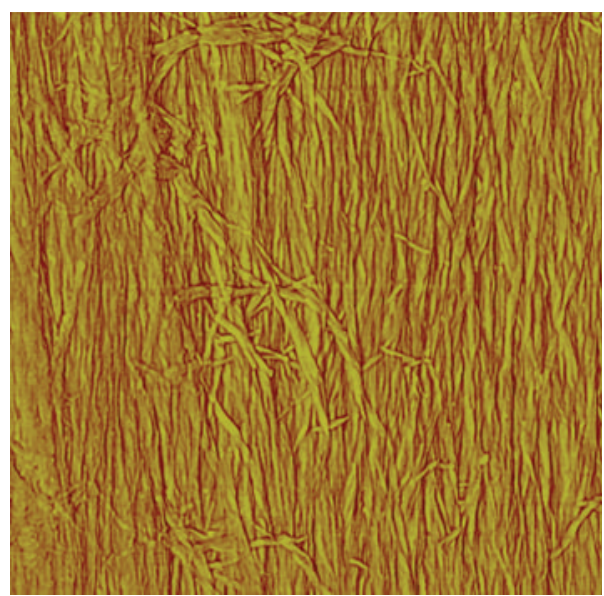

(b)

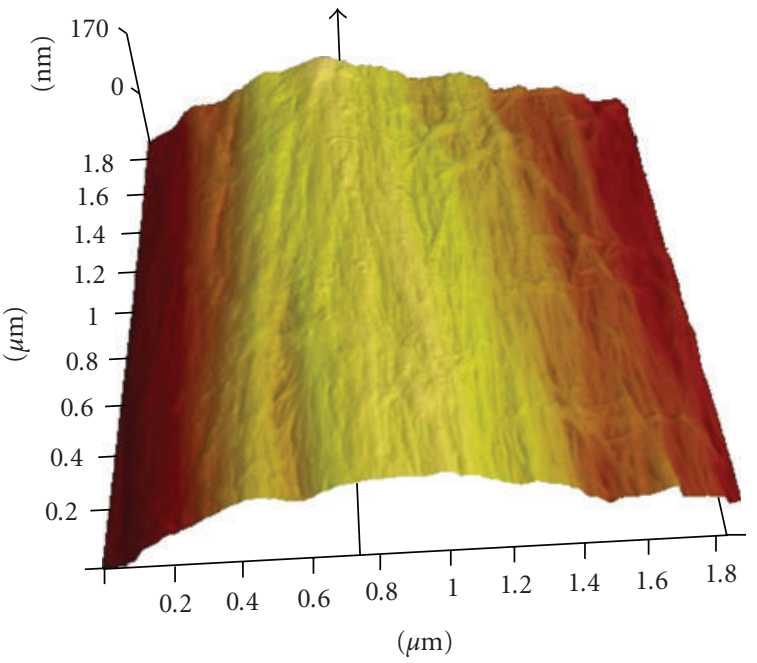

(d)

FIgURE 3: TM-AFM phase images (scan size of $4 \mu \mathrm{m}^{2}$ ) of enzyme-treated fibres of (a) 5 hours, and (b) 18 hours, (c) TM-AFM 3D phase image of the microfibrils showing their preferential orientation (scan size: $1 \mu \mathrm{m}^{2}$ ), (d) TM-AFM 3D height profile showing the main fibre axis going through the maximum height of the image.

The pectinase enzyme preparation, which contains pectolytic and a range of hemicellulolytic activities, has the ability to depolymerise major components of plant cell walls. After $5 \mathrm{H}$ of enzymatic treatment, the flax fibre still presents some large inhomogeneous and rough areas which seem to cover, like an envelope, a more organised layer made of aligned structures (Figure 3(a)). After $18 \mathrm{H}$ of treatment, a more uniform surface can be observed, showing only oriented microfibrils (Figure 3(b)). A high resolution 3D image of enzyme-treated $(18 \mathrm{H})$ flax fibre (Figure $3(\mathrm{c})$ ) allows for the visualisation of the oriented cellulose microfibrils (in the size range 25 to $30 \mathrm{~nm}$ ) and indicates the preferred orientation along the fibre longitudinal axis (Figure 3(d)). In Figure $3(\mathrm{~d})$, the axis of the fibre is indicated by the arrow that goes through the maximum heights of the fibre, and we can qualitatively observe that the microfibril angle is somehow quite close to the main fibre axis [4].
The multiscale complementary approach, using SEM and AFM, confirms the removal of some amorphous polysaccharides from the outermost surface of the flax fibres (middle and primary layers) to provide a clean and smooth surface with well-aligned cellulose microfibrils with an orientation angle close to the fibril's axis, typical of the secondary layer.

Surface chemical modifications induced by the treatments were investigated by ATR-IR spectroscopy, and the recorded spectra are displayed in Figure 4. When compared to raw flax fibre, ATR-IR spectra of treated fibres show a decrease of intensity of the peaks at $1615 \mathrm{~cm}^{-1}$ (corresponding to pectin [5]), and at $2923 \mathrm{~cm}^{-1}$ (C-H stretching vibration in hemicellulose [25]). Moreover, a shoulder peak at $1735 \mathrm{~cm}^{-1}$, that corresponds to " $\mathrm{C}=\mathrm{O}$ " stretching of carboxylic acid or ester group of hemicelluloses [26], disappeared after the treatments. These observations show that pectin and hemicelluloses are the main compounds that are removed following the treatments. However, since 


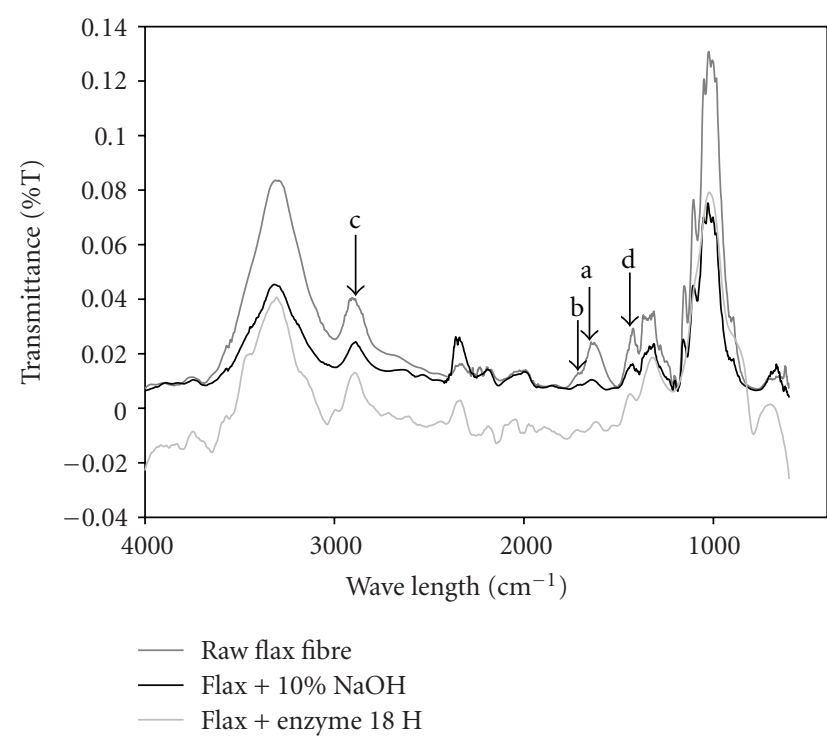

Figure 4: ATR-IR spectroscopy of raw-, NaOH-, and Enzymetreated flax fibres: (a) peak at $1615 \mathrm{~cm}^{-1}$ that corresponds to pectin; (b), (c) peaks at $1735 \mathrm{~cm}^{-1}$ and $2923 \mathrm{~cm}^{-1}$, respectively, that correspond to hemicellulose; (d) peak at $1440 \mathrm{~cm}^{-1}$ that corresponds to lignin.

the penetration depth of the ATR-IR evanescent wave is several microns, we cannot distinguish the origin of these polymers, either coming from the primary cell wall or from the secondary one.

3.2. Mechanical Properties of Flax Fibre. The tensile mechanical properties of the raw and the treated flax fibres were evaluated by the single fibre tension test (SFTT) experiment. Figure 5 represents typical stress-strain curves of different elementary flax fibres. From the raw fibre's traction curve, two distinct regions can be identified. First, a nonlinear part, from 0 to $\sim 350 \mathrm{MPa}$, is observed during low deformation at the initial stages of the loading curve. This first part can be associated with the global loading of the fibre, through the deformation of each cell wall structure [27] including a sliding of the microfibrils along their progressive alignment with the main fibre axis and a reorganisation of the amorphous matrix (mainly pectins and hemicelluloses) surrounding the microfibrils. The second region of the loading curve appears linear, characteristic of an elastic deformation, and corresponds to the response of the aligned microfibrils to the applied tensile strain. After reaching a maximum value of tensile stress, the fibre breaks. From the slope of the linear part of stress versus strain curve, one can extract a "global" (average) longitudinal Young's modulus of the fibre. The calculated Young's modulus for raw flax fibres from these experiments was found to be $65.3 \pm 16.2 \mathrm{GPa}$ (Table 1), which corresponds well with reported data $[4,27]$. Taking into account the internal composite structure of flax fibres, any discontinuity that may appear in the linear part of the stress versus strain can give information regarding any internal structural changes of the different layers of the fibres during loading.

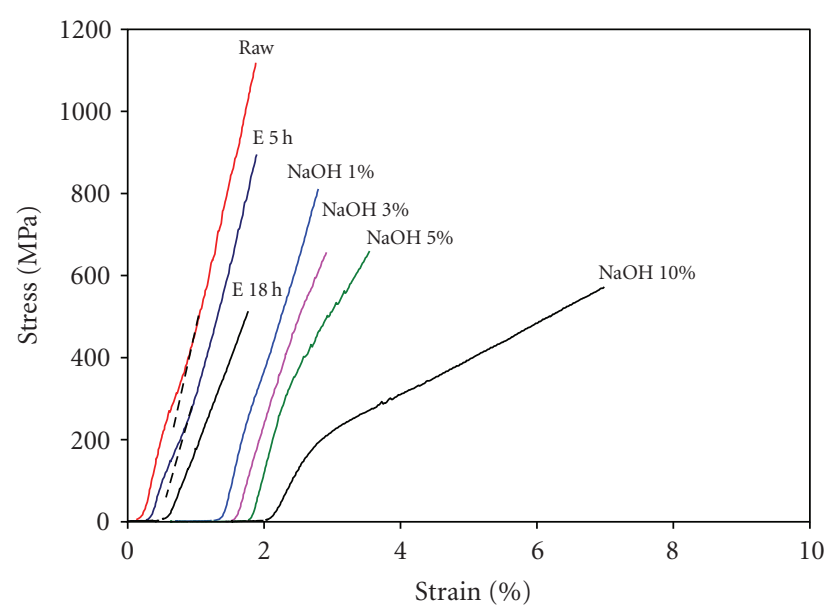

FIGURE 5: Comparison of stress versus strain curves of raw-, $\mathrm{NaOH}-$, and Enzyme-treated elementary flax fibres under tensile loading. Shaded region corresponds to a threshold stress level bellow which fibres broke before pullout in microbonding test.

Stress-strain curves obtained for alkali- and enzymatictreated flax fibres are significantly different from that of the raw flax fibre. For the $1 \% \mathrm{NaOH}$-treated fibres, the initial nonlinear part is still visible, but as the concentration of the alkali increases, the initial "nonlinear" part of the stressstrain graph disappears to give a straight and linear curve. As revealed by AFM analysis, observation of the organised and oriented microfibrils was only possible for samples treated with a $5 \% \mathrm{NaOH}$ solution. For $\mathrm{NaOH}$ concentrations of $5 \%$ and $10 \%$, the stress-strain curves present two linear regions with a transition that evolves with the increase of concentration of the sodium hydroxide solutions (up to $\sim 400 \mathrm{MPa}$ for the $5 \% \mathrm{NaOH}$-treated fibre, and up to $200 \mathrm{MPa}$ for the $10 \%$-treated one). This typical nonelastic behaviour can be related to the internal structural changes in the fibre, such as swelling, induced by the alkali treatment. The curves resemble a biphasic stress-strain curve which is typically observed in tensile loading of wood fibres [28], in which the first slope of the curve is due to the orientation of microfibrils in the direction of deformation. After a yield point, corresponding to a threshold stress, a second linear stage with a smaller slope evolved and can be interpreted as a consequence of plastic deformation of the polysaccharide matrix accompanied by a slippage mechanism of microfibrils under tensile loading [28]. Keckes et al. [29] proposed a simple "molecular Velcro" model to explain this deformation process in which a large number of molecular bonds, due to entangled hemicellulose chains, may disrupt upon stress transfer between cellulose fibrils and amorphous matrix.

In the case of these two $\mathrm{NaOH}$ treatments, traction curves observed here are likely obtained from the response of the secondary layer of the fibre, as observed by AFM. Morvan et al. [5] described the organisation of this layer and proposed a close relation between the two encrusting amorphous polymers, pectins and hemicelluloses, and crystalline cellulose microfibrils. In this system, molecular 
TABle 1: Comparison of Young's modulus $\left(E_{L}\right)$ and tensile stress $(\sigma)$ of raw-, NaOH-, and enzyme-treated flax fibres measured by single fibre tension test.

\begin{tabular}{|c|c|c|c|c|c|c|c|}
\hline & Raw flax & $1 \% \mathrm{NaOH}$ & $3 \% \mathrm{NaOH}$ & $5 \% \mathrm{NaOH}$ & $10 \% \mathrm{NaOH}$ & Enzyme $5 \mathrm{~h}$ & Enzyme $18 \mathrm{~h}$ \\
\hline Longitudinal Young's modulus $E_{L}(\mathrm{Gpa})$ & $65.3 \pm 16$ & $44.3 \pm 13$ & $40.5 \pm 10$ & $39.2 \pm 6$ & $28.5 \pm 5$ & $50.5 \pm 9$ & $43 \pm 10$ \\
\hline Tensile strength $\sigma(\mathrm{MPa})$ & $1077 \pm 250$ & $702 \pm 221$ & $649 \pm 220$ & $634 \pm 200$ & $564 \pm 193$ & $880 \pm 180$ & $527 \pm 120$ \\
\hline
\end{tabular}

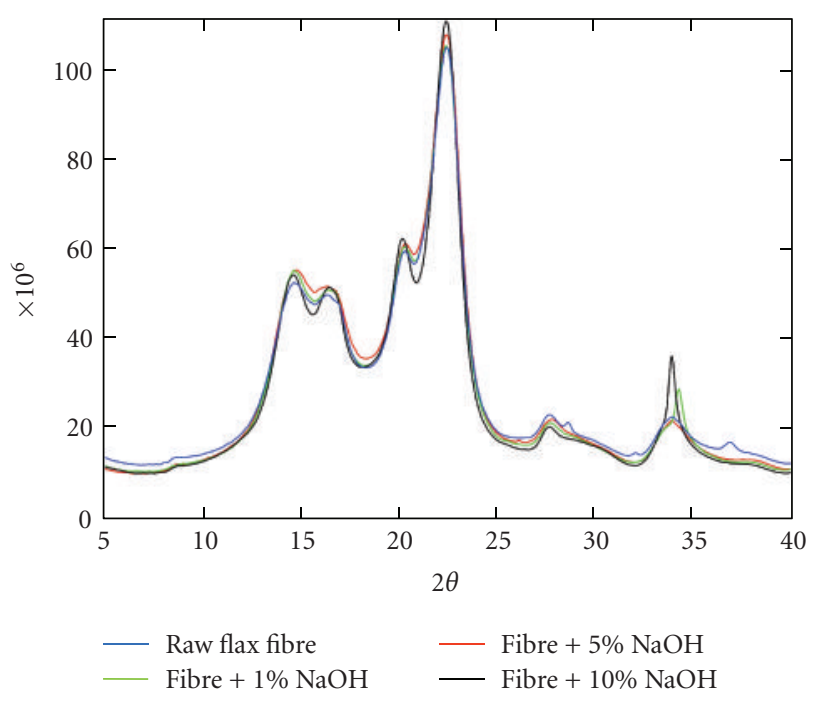

Figure 6: WAXS pattern of raw and different $\mathrm{NaOH}$-treated flax fibres.

bonds between pectin and hemicellulose, including hydrogen van der Waals interactions, may break upon loading in order to dissipate the stress and could explain the "pseudoplastic" deformation observed at $10 \%$ of $\mathrm{NaOH}$. Further, a linearly increasing slope after the deformation region can be attributed to the rearrangement of cellulose fibrils in the direction of strain [30]. Following this "severe" treatment, the $\mathrm{NaOH}$ solution may have attacked irreversibly the encrusting hemicellulose and pectin macromolecules in the secondary layer and thus weaken their ability to efficiently transfer the stress between adjacent cellulose microfibrils. The decreasing value of yield stress of fibres with increasing concentration of alkali (above $5 \% \mathrm{NaOH}$ ) is a clear indication of the severity of alkali attack on encrusting polymers, which should be avoided to conserve the good mechanical properties of the fibre. Another important feature concerns the stress at break value obtained for the different fibres. We can observe a decrease from $1100 \mathrm{MPa}$ for the raw fibre to $\sim 550 \mathrm{MPa}$, as the concentration of $\mathrm{NaOH}$ treatment was increased up to $10 \%$. Wide-angle X-ray diffraction experiments, performed on raw- and alkali-treated fibres, do not show any significant difference (Figure 6) and are typical of microcrystalline cellulose [17]. Reflection peaks at $2 \theta=$ $22.4^{\circ}, 16.4^{\circ}$, and $14.8^{\circ}$ that correspond to native cellulose I were found, as reported in the literature [31, 32]. WAXS experiments indicate that the alkali treatment conditions used in this study did not alter the crystalline part of the fibre and confirm that a polymorphic transition of cellulose I structure to cellulose II did not occur. The decrease in the stress at break for alkali-treated flax fibres can thus be preferentially attributed to an alteration of amorphous noncellulosic polysaccharides, pectins and hemicelluloses, present in the primary and secondary cell wall layers of the fibre. Furthermore, the presence of natural defects found in flax fibres, such as kink bands, may also play an important role in the decrease of the stress since they may become more brittle after treatments, due to a favourable and rapid diffusion of the alkali solution through these defects and down to the internal structure of the fibre. It has been shown earlier that, under tensile loading, the fibre starts to break at the region near the kink band where the crack initiates [33]. It is worth noting that for alkali-treated fibres, as the concentration of $\mathrm{NaOH}$ increases, the area under the stressstrain curve increases considerably. This is an important property change since the total area under the curve corresponds to the energy per unit volume absorbed in the fibre until its failure and thus to a measure of toughness of the material [28] which is interesting for some applications like energy absorption or vibration damping. Our experiments show that by controlling the $\mathrm{NaOH}$ treatment conditions, the toughness of the fibres can be tuned for specific applications.

In the case of pectinase enzyme-treated flax fibres, after 5 hrs of treatment, the shape of the stress-stain curve was similar to that of raw flax fibres (Figure 6). It showed an initial nonlinear part followed by an increasing linear part corresponding to an elastic deformation until the fibre breaks. The nonlinear initial part of the stress-strain graph indicates the presence of a significant amount of residual amorphous polymers from the primary cell wall, as observed by the AFM images. On the other hand, flax fibres treated for 18 hours show only a single linear slope that extends until the fibre breaks, which is representative of a direct elastic response of the microfibrils under loading, in good correlation with AFM observations. Contrary to $\mathrm{NaOH}-$ treated flax fibres, the enzyme-treated fibres did not show biphasic stress-strain curves, even after prolonged treatment times $(18 \mathrm{H})$. This result can be explained by the specificity of the pectinase enzyme treatment that largely acts on pectin and do not induces any swelling of the material. It is thus likely that encrusting hemicelluloses are not altered by the pectinase treatment and thus maintained the cohesion of the crystalline cellulose microfibrils within the secondary layer. This is an important result which shows that a specific enzymatic treatment is more suitable to keep the intrinsic stiffness of the flax fibres and emphasizes the important role of the encrusting amorphous hemicellulose in the secondary layer to maintain the cohesion between cellulose microfibrils. However, it should be also noted that the stress at break of $18 \mathrm{H}$ enzyme-treated fibres was comparatively less than the $5 \mathrm{H}$-treated fibres (Table 1). This behaviour can be associated 
with a possible alteration of defects such as kink bands within the fibre upon a prolonged treatment.

3.3. Adherence/Adhesion Properties. As previously discussed, another important issue in the development of biocomposites is the optimisation of the interface in order to promote a good stress transfer between the fibre and the polymer matrix. At the macroscopic scale, the microbonding pullout test is well suited to directly determine the adherence between a reinforcement fibre and the polymer matrix [34] and was thus adapted to directly measure the adherence between an elementary flax fibre and a polylactic acid polymer drop. The apparent interfacial shear stress (IFSS), $\tau_{\text {i.mean }}$, was calculated using the following Kelly-Tyson [35] equation:

$$
\tau_{i \text { mean }}=\frac{F_{\max }}{\pi d l_{e}}
$$

where $F_{\max }$ is the maximum pull-off force at debonding, $d$ is the fibre diameter, and $l_{e}$ is the fibre-embedded length in the polymer droplet. The above equation assumes that the force $F_{\max }$ at the instant of debonding is predicted to be directly proportional to the joined surface area between the fibre and matrix, and the droplet shears off from the fibre surface when the average shear stress at the interface, $\tau_{i \text { mean }}$, becomes large enough to break the interface. The apparent shear stress was determined from the linear regression of the plot of debonding force versus bonding area. The apparent interfacial shear stress values (IFSS), $\tau_{i \text {.mean }}$, calculated for PLA matrix and different flax fibres are summarized in Table 2. We observed that apparent IFSS values improved after both treatments. In both cases, the maximum IFSS values were obtained for the mild treatment conditions, that is, at $1 \%$ of $\mathrm{NaOH}$ and after $5 \mathrm{H}$ of enzymatic treatment. However, for more aggressive treatment conditions, that is, at $5 \% \mathrm{NaOH}, 10 \% \mathrm{NaOH}$, and $18 \mathrm{H}$ enzyme treatments, IFSS values were not validated since the fibres break cohesively before the complete pull-out event during microbond testing. Earlier, the elastic properties of these fibres (Figure 5) were shown to be greatly reduced when the treatments reached the secondary layers and attacked the encrusting polymers. It was observed that successful fibre pull-out tests were obtained for fibres with tensile strength values above a threshold stress level of $\sim 800 \mathrm{MPa}$. Similar observations were already reported by Pommet et al. [36] on bacterial cellulosemodified sisal fibres/PLA system where cohesive failure of the fibre occurred when interfacial adhesion exceeded the adhesion among the different constituents of the fibre.

An improved adhesion between modified fibre and the PLA polymer can be developed through different mechanisms. For example, Pommet et al. [36] suggested that the presence of cellulose microfibrils increases the roughness of the fibre's surface, that may enhance the adhesion through mechanical interlocking mechanisms. Other explanations such as the presence of hydrogen bonds between hydroxyl groups present on cellulose fibrils and carbonyl groups in PLA were also argumented [36]. The hypothesis of the fibre's roughness is not validated here since the fibre becomes smoother after the treatment, as revealed by AFM; however, we expect some strong interactions between cellulose fibrils and PLA polymer when some weakly adhering polysaccharides are removed from the fibres, through, for example, hydrogen and van der Waals interactions [37]. However, the pull-out test cannot directly distinguish the nature of these different adhesion interactions.

In a recent work [38], we demonstrate that the force volume technique provides valuable information on the adhesion properties of heterogeneous natural fibres at the nanoscopic scale. Force volume displays simultaneously a topographic image of the fibre surface and the corresponding adhesion map between the fibre surface and a standard silicon nitride AFM tip. The adhesion mapping is obtained from the measurement of force-distance curves on all the different coordinates of the fibres' scanned area (Figure 7). The topographic height image of the sample is crucial in the interpretation of adhesion force maps, since the adhesion interaction between the tip and the sample is dependent on the contact area between the tip and sample. For heterogeneous flax samples, the technique allows for a semiquantitative comparison of the changes in the topography and adhesion properties of raw and different treated fibres.

The adhesion map of raw flax fibres (Figure 7(b)) reveals a heterogeneous distribution of adhesion forces across the fibre surface. Some large aggregates can be found on the outer surface of the raw fibre, as already discussed in the first part. High values of adhesion forces were recorded on such compounds, as indicated by darker regions in the adhesion map image. Average adhesion forces measured on raw flax fibre surface ranged from 41 to $73 \mathrm{nN}$. FV images of alkali-(Figure 7(e)) and enzymatic-treated fibres (Figure $7(\mathrm{~h})$ ) contrast well with those of raw flax fibres. In the latter case, a more homogeneous fibre surface can be observed. The adhesion peaks of the force plots are all superposed and present a small adhesion with the AFM tip. The adhesion forces measured on the treated fibres ranged from 6.5 to $10 \mathrm{nN}$.

In the absence of electrostatic and chemical bonding forces, adhesion between an AFM tip and the fibre's surface results mainly from van der Waals interactions and capillary forces that arise from condensation of water molecules, present in ambient conditions (56\% of relative humidity), between the tip and the surface [39]. Thus, under ambient humidity, adhesion forces are largely influenced by capillary forces, which in turn are dependent on the hydrophilic/hydrophobic properties of the surface and the AFM tip. The latter is known to be hydrophilic. Generally, for hydrophilic surfaces, increased relative humidity leads to an increase of the capillary forces [40]. On the other hand, if the surface is hydrophobic in nature, the contribution from the capillary forces on the adhesion force measurements is less and can even be independent of relative humidity [41]. Thus, we presume that high adhesion forces measured on raw flax fibres are mainly due to the presence of pectin materials that is known to be the more hydrophilic polysaccharide [42] in the fibre and present in the middle lamellae and the primary layer. When this polysaccharide 


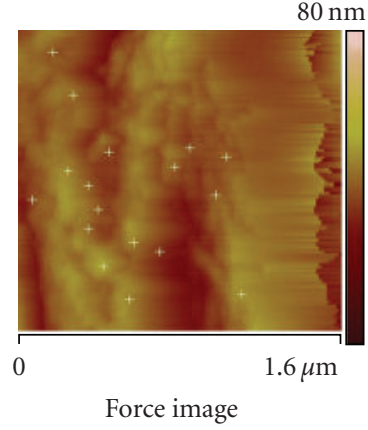

(a)

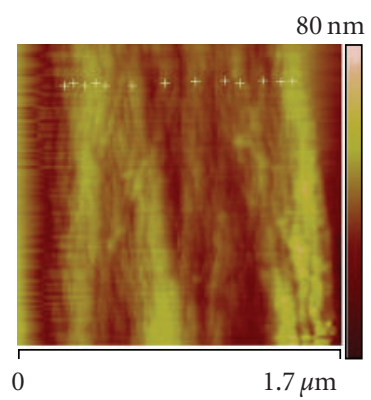

Force image

(d)

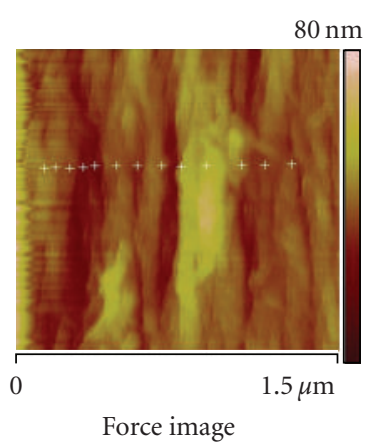

(g)

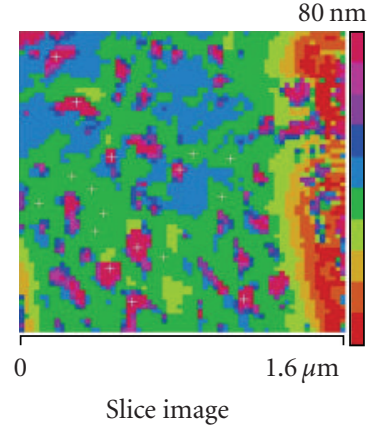

(b)

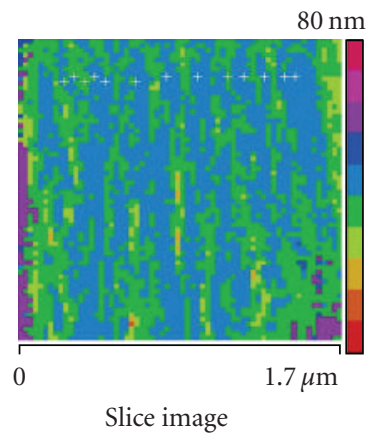

(e)

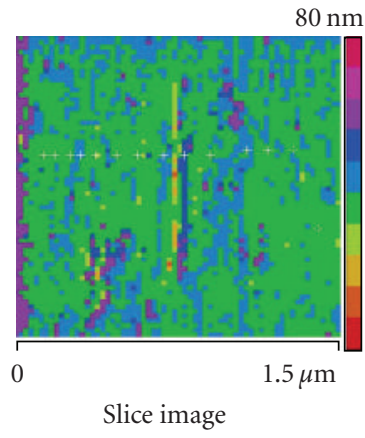

(h)

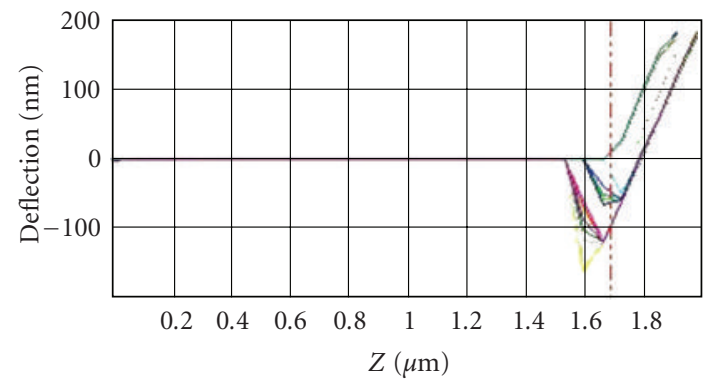

(c)

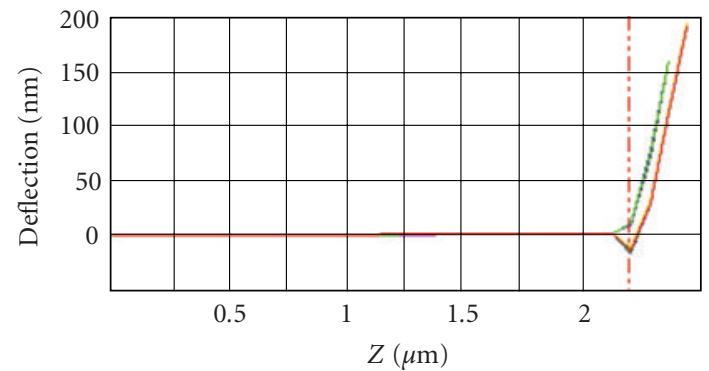

(f)

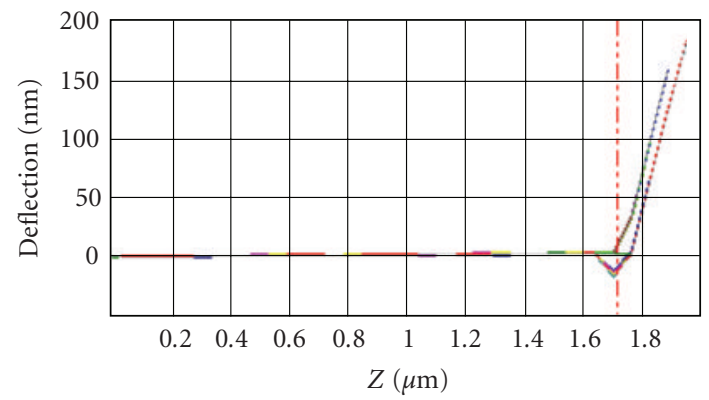

(i)

FIGURE 7: AFM Force-volume images: topography, FV adhesion force map, and force plots corresponding to raw flax fibres ((a), (b), and (c), resp.); $\mathrm{NaOH}$-treated fibres ((d), (e), and (f), resp.); enzyme-treated flax ((g), (h), and (i), resp.).

is removed from the fibre's surface as a consequence of the treatment, as revealed by AFM, the outer surface is mainly constituted by cellulose microfibrils, which in turn gives to the fibre different chemical properties. Biermann et al. [43] studied the chemical nature of crystalline cellulose surface by dynamic molecular simulations and reported a nonhydrophilic nature. Another recent study by Zykwinska et al. [44] reported that the (llll $\left.00 \begin{array}{l}0 \\ 0\end{array}\right)$ crystal plane of cellulose is hydrophobic since $\mathrm{CH}$ groups are exposed at the surface, whereas the $\mathrm{OH}$ groups are reported to form specific types of hydrogen bonds within the crystalline regions [45]. These findings suggest that crystalline regions in cellulose are rather hydrophobic in regards of the amorphous polysaccharides which can present free hydroxyl groups and consequently may form hydrogen bonds with water molecules on the surface. This hypothesis is in good agreement with the lower adhesion forces measured on treated fibres. These results are also well correlated with the microbond test. The low adhesion forces measured by force volume are synonymous of a surface that is less hydrophilic, which may lead to a higher adhesion with the rather hydrophobic PLA matrix.

\section{Conclusion}

The effect of alkali and enzymatic treatments on the fibre's structure, surface composition, and adhesion properties was investigated. A major consequence of these treatments is the removal of some weakly adhering amorphous polysaccharides, mainly pectins and hemicelluloses, essentially from the middle lamellae, primary cell wall and possibly from the secondary cell wall, as observed by AFM. The organisation 
TABLE 2: Interfacial shear stress values of raw-, $\mathrm{NaOH}-$, and enzyme-treated flax fibres calculated from microbonding test with a PLA droplet.

\begin{tabular}{lcccccc}
\hline & Raw flax & $1 \% \mathrm{NaOH}$ & $5 \% \mathrm{NaOH}$ & $10 \% \mathrm{NaOH}$ & Enzyme $5 \mathrm{~h}$ & Enzyme $18 \mathrm{~h}$ \\
\hline IFSS $(\mathrm{MPa})$ & $14.5 \pm 4$ & $20.5 \pm 3.6$ & Not obtained & Not obtained & $19.5 \pm 3.3$ & Not obtained \\
\hline
\end{tabular}

of these polymers within these layers was found to have a profound impact on the overall mechanical properties of the fibre, as revealed by traction tests on elementary fibres. We demonstrate that pectins and hemicelluloses, in the primary layer, do not significantly impact the mechanical properties of the fibre, whereas more pronounced treatments, that reach the secondary layer and attack encrusting polymers, may decrease the strength of the fibre, by reducing the interactions between amorphous and crystalline polymers. In parallel, adhesion properties of the treated fibres were examined at different scales and proved to be essential in the optimisation of a composite system. Microbond tests reveal that PLA adhesion on the flax secondary layer with oriented cellulose microfibrils was found to be the most important, through different mechanisms, mainly van der Waals interactions and $\mathrm{H}$ bonding. For an optimal performance of biocomposites, an improvement in interface adhesion with PLA while preserving flax fibre intrinsic mechanical properties was achieved here at gentle alkali treatments (1\%, for 20 minutes) and more safely by enzymatic treatments (up to $5 \mathrm{Hrs}$ ). The latter ecofriendly treatment proves that this process is becoming highly attractive in the biocomposite industry.

\section{Acknowledgments}

Financial support for this work from Region Bretagne, Cap Lorient, and the Morbihan Department (France) is deeply acknowledged. The Authors thank Professor Dimitri A. Ivanov, ICSI, Mulhouse (France) for performing WAXS experiments on flax fibres.

\section{References}

[1] E. Bodros, I. Pillin, N. Montrelay, and C. Baley, "Could biopolymers reinforced by randomly scattered flax fibre be used in structural applications?" Composites Science and Technology, vol. 67, no. 3-4, pp. 462-470, 2007.

[2] D. Plackett, T. L. Andersen, W. B. Pedersen, and L. Nielsen, "Biodegradable composites based on L-polylactide and jute fibres," Composites Science and Technology, vol. 63, no. 9, pp. 1287-1296, 2003.

[3] K. Oksman, M. Skrifvars, and J. F. Selin, "Natural fibres as reinforcement in polylactic acid (PLA) composites," Composites Science and Technology, vol. 63, no. 9, pp. 1317-1324, 2003.

[4] C. Baley, "Analysis of the flax fibres tensile behaviour and analysis of the tensile stiffness increase," Composites A, vol. 33, no. 7, pp. 939-948, 2002.

[5] C. Morvan, C. Andème-Onzighi, R. Girault, D. S. Himmelsbach, A. Driouich, and D. E. Akin, "Building flax fibres: more than one brick in the walls," Plant Physiology and Biochemistry, vol. 41, no. 11-12, pp. 935-944, 2003.

[6] H. L. Bos, J. Müssig, and M. J. A. van den Oever, "Mechanical properties of short-flax-fibre reinforced compounds," Composites A, vol. 37, no. 10, pp. 1591-1604, 2006.
[7] K. Charlet, J. P. Jernot, M. Gomina, J. Bréard, C. Morvan, and C. Baley, "Influence of an Agatha flax fibre location in a stem on its mechanical, chemical and morphological properties," Composites Science and Technology, vol. 69, no. 9, pp. 13991403, 2009.

[8] A. Šturcová, G. R. Davies, and S. J. Eichhorn, "Elastic modulus and stress-transfer properties of tunicate cellulose whiskers," Biomacromolecules, vol. 6, no. 2, pp. 1055-1061, 2005.

[9] A. K. Mohanty, M. Misra, and L. T. Drzal, "Surface modifications of natural fibers and performance of the resulting biocomposites: an overview," Composite Interfaces, vol. 8, no. 5, pp. 313-343, 2001.

[10] S. Kalia, B. S. Kaith, and I. Kaur, "Pretreatments of natural fibers and their application as reinforcing material in polymer composites-a review," Polymer Engineering and Science, vol. 49, no. 7, pp. 1253-1272, 2009.

[11] A. Arbelaiz, G. Cantero, B. Fernández, I. Mondragon, P. Gañán, and J. M. Kenny, "Flax fiber surface modifications: effects on fiber physico mechanical and flax/polypropylene interface properties," Polymer Composites, vol. 26, no. 3, pp. 324-332, 2005.

[12] I. Van de Weyenberg, T. Chi Truong, B. Vangrimde, and I. Verpoest, "Improving the properties of UD flax fibre reinforced composites by applying an alkaline fibre treatment," Composites A, vol. 37, no. 9, pp. 1368-1376, 2006.

[13] J. Gassan and A. K. Bledzki, "Alkali treatment of jute fibers: relationship between structure and mechanical properties," Journal of Applied Polymer Science, vol. 71, no. 4, pp. 623-629, 1999.

[14] L. Y. Mwaikambo and M. P. Ansell, "Chemical modification of hemp, sisal, jute, and kapok fibers by alkalization," Journal of Applied Polymer Science, vol. 84, no. 12, pp. 2222-2234, 2002.

[15] H. S. S. Sharma, L. Whiteside, and K. Kernaghan, "Enzymatic treatment of flax fibre at the roving stage for production of wet-spun yarn," Enzyme and Microbial Technology, vol. 37, no. 4, pp. 386-394, 2005.

[16] D. E. Akin, J. A. Foulk, R. B. Dodd, and D. D. McAlister, "Enzyme-retting of flax and characterization of processed fibers," Journal of Biotechnology, vol. 89, no. 2-3, pp. 193-203, 2001.

[17] P. A. Penttilä, A. Várnai, K. Leppänen et al., "Changes in submicrometer structure of enzymatically hydrolyzed microcrystalline cellulose," Biomacromolecules, vol. 11, no. 4, pp. 1111-1117, 2010.

[18] M. Z. Rong, M. Q. Zhang, Y. Liu, G. C. Yang, and H. M. Zeng, "The effect of fiber treatment on the mechanical properties of unidirectional sisal-reinforced epoxy composites," Composites Science and Technology, vol. 61, no. 10, pp. 1437-1447, 2001.

[19] S. Marais, F. Gouanvé, A. Bonnesoeur et al., "Unsaturated polyester composites reinforced with flax fibers: effect of cold plasma and autoclave treatments on mechanical and permeation properties," Composites A, vol. 36, no. 7, pp. 975986, 2005.

[20] A. Jähn, M. W. Schröder, M. Füting, K. Schenzel, and W. Diepenbrock, "Characterization of alkali treated flax fibres by means of FT Raman spectroscopy and environmental scanning electron microscopy," Spectrochimica Acta A, vol. 58, no. 10, pp. 2271-2279, 2002. 
[21] C. Baley, F. Busnel, Y. Grohens, and O. Sire, "Influence of chemical treatments on surface properties and adhesion of flax fibre-polyester resin," Composites A, vol. 37, no. 10, pp. 16261637, 2006.

[22] A. Pietak, S. Korte, E. Tan, A. Downard, and M. P. Staiger, "Atomic force microscopy characterization of the surface wettability of natural fibres," Applied Surface Science, vol. 253, no. 7, pp. 3627-3635, 2007.

[23] E. Balnois, F. Busnel, C. Baley, and Y. Grohens, "An AFM study of the effect of chemical treatments on the surface microstructure and adhesion properties of flax fibres," Composite Interfaces, vol. 14, no. 7-10, pp. 715-731, 2007.

[24] K. Joseph, L. H. C. Mattoso, R. D. Toledo et al., "Natural fiber reinforced thermoplastic composites," in Natural Polymers and Agrofibers Composites, E. Frollini, A. L. Leao, and L. H. C. Mattoso, Eds., pp. 159-202, Embrapa, USP/ UNESP, San Carlos, Brazil, 2000.

[25] C. H. Chen, C. Y. Chen, Y. W. Lo, C. F. Mao, and W. T. Liao, "Characterization of alkali-treated jute fibers for physical and mechanical properties," Journal of Applied Polymer Science, vol. 80, no. 7, pp. 1013-1020, 2001.

[26] J. T. Kim and A. N. Netravali, "Mercerization of sisal fibers: effect of tension on mechanical properties of sisal fiber and fiber-reinforced composites," Composites A, vol. 41, no. 9, pp. 1245-1252, 2010.

[27] K. Charlet, C. Baley, C. Morvan, J. P. Jernot, M. Gomina, and J. Bréard, "Characteristics of Hermès flax fibres as a function of their location in the stem and properties of the derived unidirectional composites," Composites A, vol. 38, no. 8, pp. 1912-1921, 2007.

[28] P. Fratzl, I. Burgert, and H. S. Gupta, "On the role of interface polymers for the mechanics of natural polymeric composites," Physical Chemistry Chemical Physics, vol. 6, no. 24, pp. 55755579, 2004.

[29] J. Keckes, I. Burgert, K. Frühmann et al., "Cell-wall recovery after irreversible deformation of wood," Nature Materials, vol. 2, no. 12, pp. 810-814, 2003.

[30] C. M. Altaner and M. C. Jarvis, "Modelling polymer interactions of the 'molecular Velcro' type in wood under mechanical stress," Journal of Theoretical Biology, vol. 253, no. 3, pp. 434$445,2008$.

[31] E. Zini, M. Scandola, and P. Getenholm, "Heterogeneous acylation of flax fibers. Reaction kinetics and surface properties," Biomacromolecules, vol. 4, no. 3, pp. 821-827, 2003.

[32] S. Borysiak and J. Garbarczyk, "Applying the WAXS method to estimate the supermolecular structure of cellulose fibres after mercerisation," Fibres and Textiles in Eastern Europe, vol. 11, no. 5, pp. 104-106, 2003.

[33] C. Baley, "Influence of kink bands on the tensile strength of flax fibers," Journal of Materials Science, vol. 39, no. 1, pp. 331334, 2004.

[34] A. Straub, M. Slivka, and P. Schwartz, "A study of the effects of time and temperature on the fiber/matrix interface strength using the microbond test," Composites Science and Technology, vol. 57, no. 8, pp. 991-994, 1997.

[35] A. Kelly and W. R. Tyson, "Tensile properties of fibre-reinforced metals: copper/tungsten and copper/molybdenum," Journal of the Mechanics and Physics of Solids, vol. 13, no. 6, pp. 329-338, 1965.

[36] M. Pommet, J. Juntaro, J. Y. Y. Heng et al., "Surface modification of natural fibers using bacteria: depositing bacterial cellulose onto natural fibers to create hierarchical fiber reinforced nanocomposites," Biomacromolecules, vol. 9, no. 6, pp. 1643-1651, 2008.
[37] G. Raj, E. Balnois, C. Baley, and Y. Grohens, "Probing cellulose/polylactic acid interactions in model biocomposite by colloidal force microscopy," Colloids and Surfaces A, vol. 352, no. 1-3, pp. 47-55, 2009.

[38] G. Raj, E. Balnoiso, C. Baley, and Y. Grohens, "Adhesion force mapping of raw and treated flax fibres using afm forcevolume," Journal of Scanning Probe Microscopy, vol. 4, no. 2, pp. 66-72, 2009.

[39] H. J. Butt, B. Cappella, and M. Kappl, "Force measurements with the atomic force microscope: technique, interpretation and applications," Surface Science Reports, vol. 59, no. 1-6, pp. $1-152,2005$.

[40] D. L. Sedin and K. L. Rowlen, "Adhesion forces measured by atomic force microscopy in humid air," Analytical Chemistry, vol. 72, no. 10, pp. 2183-2189, 2000.

[41] R. Jones, H. M. Pollock, J. A. S. Cleaver, and C. S. Hodges, "Adhesion forces between glass and silicon surfaces in air studied by AFM: effects of relative humidity, particle size, roughness, and surface treatment," Langmuir, vol. 18, no. 21, pp. 8045-8055, 2002.

[42] R. Sun, J. M. Fang, and J. Tomkinson, "Characterization and esterification of hemicelluloses from rye straw," Journal of Agricultural and Food Chemistry, vol. 48, no. 4, pp. 1247-1252, 2000.

[43] O. Biermann, E. Hädicke, S. Koltzenburg, and F. MüllerPlathe, "Hydrophilicity and lipophilicity of cellulose crystal surfaces," Angewandte Chemie-International Edition, vol. 40, no. 20, pp. 3822-3825, 2001.

[44] A. Zykwinska, J. F. Thibault, and M. C. Ralet, "Modelling of xyloglucan, pectins and pectic side chains binding onto cellulose microfibrils," Carbohydrate Polymers, vol. 74, no. 1, pp. 23-30, 2008.

[45] A. J. Michell and H. G. Higgins, "The absence of free hydroxyl groups in cellulose," Cellulose, vol. 6, no. 1, pp. 89-91, 1999. 

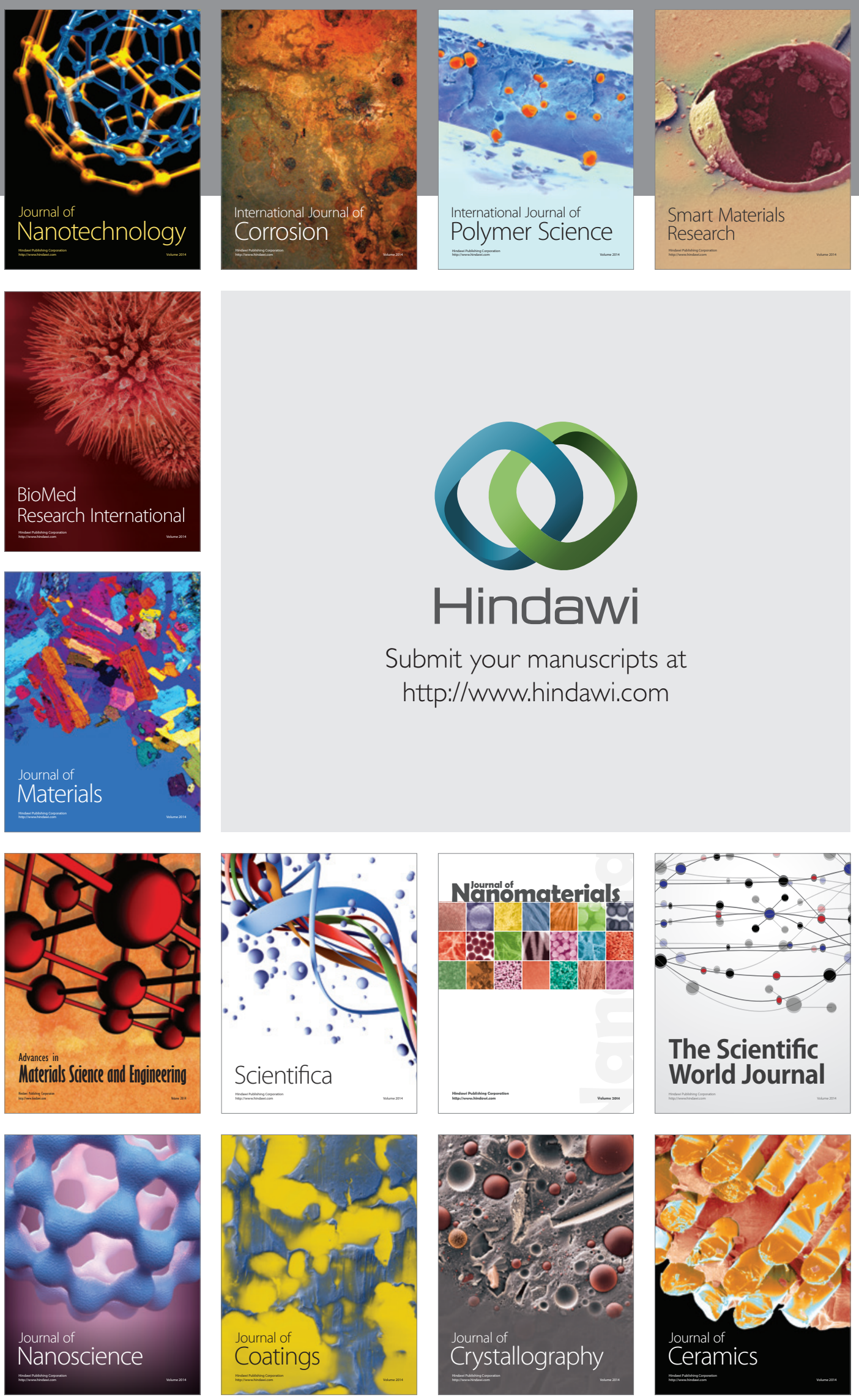

The Scientific World Journal

Submit your manuscripts at

http://www.hindawi.com

\section{World Journal}

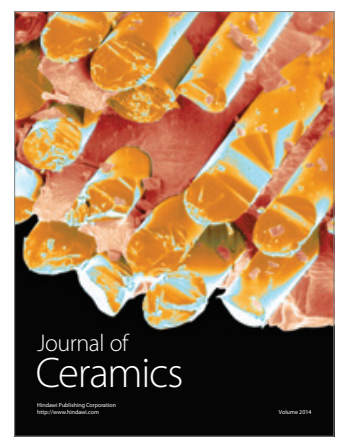

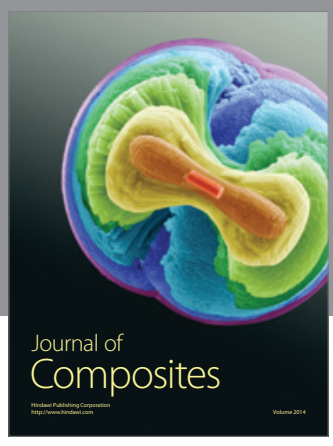
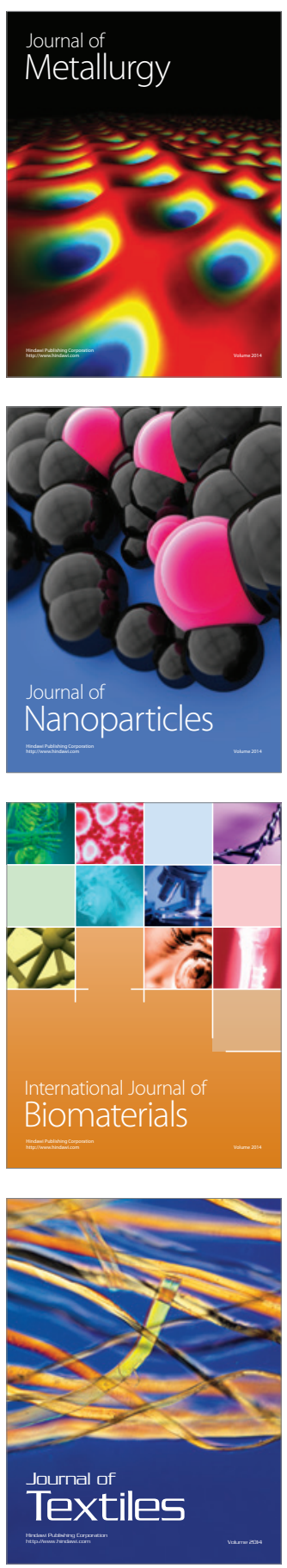